\title{
Molecular and Biological Characterization of Tomato mottle mosaic virus and Development of RT-PCR Detection
}

\author{
Xuelian Sui, USDA-Agricultural Research Service, U.S. Vegetable Laboratory, Charleston, SC, and Department of Plant Protection, Fujian \\ Agriculture and Forest University, Fuzhou, China; Yi Zheng, Boyce Thompson Institute, Cornell University, Ithaca, NY; Rugang Li and \\ Chellappan Padmanabhan, USDA-Agricultural Research Service, U.S. Vegetable Laboratory, Charleston, SC; Tongyan Tian, Plant Pest \\ Diagnostics Center, California Department of Food and Agriculture, Sacramento; Deborah Groth-Helms, Agdia Inc., Elkhart, IN; Anthony \\ P. Keinath, Clemson University, Coastal Research and Education Center, Charleston, SC; Zhangjun Fei, Boyce Thompson Institute, Cornell \\ University, Ithaca, NY, and USDA-Agricultural Research Service, Robert W. Holley Center for Agriculture and Health, Ithaca, NY; Zujian \\ Wu, Department of Plant Protection, Fujian Agriculture and Forest University, Fuzhou, China; and Kai-Shu Ling, USDA-Agricultural Re- \\ search Service, U.S. Vegetable Laboratory, Charleston, SC
}

\begin{abstract}
Tomato mottle mosaic virus (ToMMV) was first identified in 2013 as a novel tobamovirus infecting tomatoes in Mexico. In just a few years, ToMMV has been identified in several countries around the world, including the United States. In the present study, we characterized the molecular, serological, and biological properties of ToMMV and developed a species-specific RT-PCR to detect three tomato-infecting tobamoviruses: Tobacco mosaic virus (TMV), Tomato mosaic virus (ToMV), and ToMMV. Previously, ToMMV has been reported in Florida and New York. In this study, we made two new reports on the occurrences of ToMMV on tomatoes in California and South Carolina. Their complete genome sequences were obtained and their genetic relationships

to other tobamoviruses evaluated. In host range studies, some differential responses in host plants were also identified between ToMMV and ToMV. To alleviate cross-serological reactivity among the tomatoinfecting tobamoviruses, a new multiplex RT-PCR was developed to allow for species-specific detection and identification of TMV, ToMV, and ToMMV. In addition, we observed resistance breaking by ToMMV on selected tomato cultivars that were resistant to ToMV. This has caused serious concerns to tomato growers worldwide. In conclusion, the characterization in molecular and biological properties of ToMMV would provide us with fundamental knowledge to manage this emerging virus on tomato and other solanaceous crops in the U.S. and around the world.
\end{abstract}

Tomato (Solanum lycopersicum L.) is one of the most important vegetable crops in the world (Foolad and Panthee 2012). The United States is the second largest producer of tomatoes, only after China (USDA-NASS 2015). Diseases caused by viruses are one of the most critical factors affecting tomato production worldwide (Hanssen et al. 2010; Hajiabadi et al. 2012; Imran et al. 2012; Lefeuvre et al. 2010; Tentchev et al. 2011; Webster et al. 2015). Tobacco mosaic virus (TMV) and Tomato mosaic virus (ToMV) are two of the most recognizable and economically important viruses infecting tomato (Hanssen et al. 2010). In 2013, using deep sequencing and assembly of small RNAs (Zheng et al. 2017; http://bioinfo.bti.cornell.edu/tool/ VirusDetect/), Tomato mottle mosaic virus (ToMMV) was discovered in Mexico for the first time as a third tobamovirus infecting tomato crops (Li et al. 2013). Subsequently, this virus was identified on tomato or pepper plants in Florida (Fillmer et al. 2015) and New York (Padmanabhan et al. 2015) in the United States, as well as China ( $\mathrm{Li}$ et al. 2014) and Israel (Turina et al. 2016). In 2015, the fourth tobamovirus, Tomato brown rugose fruit virus (TBRFV), was identified in Jordan infecting tomatoes (Salem et al. 2016). Analysis of the genome sequence in TMV-Ohio V (GenBank accession no. FR878069), originally considered as a novel genotype of TMV (Körbelin et al. 2012), revealed less than $90 \%$ nucleotide sequence identities to other known tobamoviruses. Although authors did not name TMV Ohio V as a novel species (Körbelin et al. 2012), such unique genome sequence in TMV Ohio V should be considered as a new species of tobamovirus based on the International Committee on Taxonomy of Viruses (ICTV) demarcation criteria (Adams et al. 2012).

Corresponding author: Kai-Shu Ling, E-mail: kai.ling@ars.usda.gov

*The $\boldsymbol{e}$-Xtra logo stands for "electronic extra" and indicates that one supplementary table and two supplementary figures are available online.

Accepted for publication 22 December 2016.

This article is in the public domain and not copyrightable. It may be freely reprinted with customary crediting of the source. The American Phytopathological Society, 2017.
ToMMV-infected tomato plants are stunted and display severe mosaic symptoms and leaf distortion (Li et al. 2013). Comparative genome sequence analysis classified ToMMV as a distinct virus species, with $80 \%$ nucleotide sequence identity to TMV and $85 \%$ to ToMV (Li et al. 2013). However, the biological and serological properties of this emerging virus have not been characterized.

An effective disease management program is dependent on timely and proper identification to the causal agent of a disease. This is especially important for a field-collected sample, where mixed infection of multiple viruses is quite common. For tomato-infecting tobamoviruses, the most common method of virus detection using a serological technology, such as ELISA or a lateral flow device, could not make a definite species-specific identification. In light of multiple tobamoviruses infecting tomatoes and each with some unique biological properties, the demand for species-specific identification is especially strong. Previous studies demonstrated possibility in developing species-specific detection of tobamoviruses using reverse transcription (RT)-PCR. Letschert et al. (2002) developed an immunocapture RT-PCR system to detect five individual tobamoviruses, including TMV and ToMV. A multiplex immunocapture RT-PCR assay was developed to allow for a simultaneous detection and differentiation of TMV and ToMV in spruce and pine extracts (Jacobi et al. 1998). Using sequences from a different virus genome region, another multiplex RT-PCR was developed for TMV and ToMV detection in tomato and pepper seeds (Kumar et al. 2011). However, due to the recent discovery of ToMMV (Li et al. 2013) and other closely related tobamoviruses (Körbelin et al. 2012; Salem et al. 2016), the primers used for RT-PCR in previous studies need to be examined and redesigned in order to achieve a reliable species-specific identification.

Tomato-infecting tobamoviruses are seed-borne (on seed coat, not seed-transmitted) viruses that could be easily transmitted to tomato seedlings through contacts made to contaminated seeds or during cultivation (Chitra et al. 2002). Diseases caused by these highly contagious viruses are difficult to control. Planting a disease-resistant cultivar is a most effective means of disease management against ToMV in tomato production. $T m-1, T m-2$, and $T m 2^{2}$ genes genetically confer ToMV resistance (Lanfermeijer et al. 2003; Ohmori et al 
1996; Pelham 1966; Young et al. 1988). The TM-1 gene, derived from the wild tomato species $S$. habrochaites, confers resistance to ToMV strains 0 and 2. $T m-2$ and $T m 2^{2}$ genes were introgressed from $S$. peruvianum and are considered allelic. Tm-2 confers resistance to ToMV strains 0 and 1 , whereas $T m 2^{2}$ confers resistance to strains 0,1 , and 2 (Shi et al. 2011). Among these resistance genes, $T m-2$ and $T m-2^{2}$ induce a plant defense reaction in tomato plants by recognizing the movement proteins of TMV and ToMV (Liu et al. 1999; Weber et al. 2004). Both resistance genes and their molecular markers useful for marker-assisted selection have been developed and used for tomato breeding for ToMV resistance (Shi et al. 2011). However, in some cases, even a small number of amino acid substitutions in the virus genome can overcome this resistance mechanism (Hamamoto et al. 1997; Strasser and Pfitzner 2007; Weber et al. 1993). Thus, it is necessary to test whether ToMMV has the ability to break resistance on existing commercial tomato cultivars.

In the present study, we determined the complete genome sequences of two new ToMMV isolates collected from two separate regions in the United States, California and South Carolina. By comparing their genome sequences with other tomato-infecting tobamoviruses, we selected the conserved but species-unique primer sequences to develop a multiplex RT-PCR detection to allow for a species-specific and sensitive detection and identification of ToMMV, TMV, and ToMV in a single reaction. We also compared the experimental host ranges for ToMMV and ToMV to identify any plant species that are unique for ToMMV. Finally, through mechanical inoculation, we observed a partial resistance breaking by ToMMV on a tomato cultivar 'B', which is resistant to ToMV.

\section{Materials and Methods}

Virus isolates and mechanical inoculation. The ToMMV isolate MX5 was originally collected in tomato plants from a greenhouse in Mexico (Li et al. 2013). A second ToMMV isolate (CA16-01) was collected from a greenhouse in California in 2016, and a third ToMMV isolate (SC13-05) was collected from a greenhouse in South Carolina in 2013. The individual virus isolates were maintained on 'Moneymaker' tomato plants within an insect-proof bug dome kept in a greenhouse at 25 to $30^{\circ} \mathrm{C}$. A ToMV isolate (V1307) was collected on tomato from California and a TMV isolate was provided by Agdia (Elkhart, IN), which were confirmed to be the respective ToMV or TMV using the species-specific RT-PCR developed in the present study and by sequencing. For virus inoculation, healthy plants at the 2- to 3-leaf stage were lightly dusted with Carborundum (320-grit) and gently inoculated with a cotton swab soaked in an inoculum prepared $(1: 5 \mathrm{w} / \mathrm{v})$ in a $1 \times$ phosphatebuffered saline solution, pH $7.0\left(140 \mathrm{mM} \mathrm{NaCl}, 8 \mathrm{mM} \mathrm{Na}_{2} \mathrm{HPO}_{4}\right.$, $1.5 \mathrm{mM} \mathrm{KH}_{2} \mathrm{PO}_{4}, 2.7 \mathrm{mM} \mathrm{KCl}$, and $0.8 \mathrm{mM} \mathrm{Na}_{2} \mathrm{SO}_{3}$ ). After rinsing, inoculated plants were placed in the shade for a few hours before transferring to a greenhouse for symptom observation. In addition, Cucumber green mottle mosaic virus (CGMMV) and Pepper mild mottle virus (PMMoV), as well as several tomato-infecting viruses, including TBRFV, Pepino mosaic virus (PepMV), Tomato spotted wilt virus (TSWV), Tomato chlorotic spot virus (TCSV), Tomato yellow leaf curl virus (TYLCV), and Potato spindle tuber viroid (PSTVd), were used to evaluate the specificity of multiplex RT-PCR

Host range. To compare the experimental host range between ToMMV and ToMV, 27 plant species from seven families (i.e., Amaranthaceae, Apocynaceae, Asteraceae, Brassicaceae, Cucurbitaceae, Solanaceae, and Verbenaceae) were germinated and maintained in a greenhouse. For each plant species, two to seven plants at the 2- to 3-leaf stage were mechanically inoculated with the respective isolate of ToMMV or ToMV as described earlier. To determine virus infection, symptom development on the local inoculated leaves and the upper systemic leaves was observed weekly for 4 to 6 weeks post inoculation. The presence of ToMV on the systemic leaves at the conclusion of an experiment was also determined using a commercial ELISA kit and species-specific RT-PCR tests as described in the following.

Sequencing of two new ToMMV isolates. For the ToMMV isolate SC13-05, total plant RNA was extracted from an infected tomato plant using TRIzol reagent according to the manufacturer's instructions (Thermal Fisher Scientific, U.S.A.). After isolation of small RNA (sRNA) from an acrylamide gel, an sRNA library was prepared as described by Chen et al. (2012) and sequenced using Illumina HiSeq 2000. Small RNA sequence reads were assembled and viruses identified using the VirusDetect bioinformatics pipeline (Zheng et al. 2017; http://bioinfo.bti.cornell.edu/tool/VirusDetect/). The full genome sequence of the ToMMV-California isolate (CA16-01) was assembled using Sanger sequencing to a series of overlapping RT-PCR amplicons, generated using 10 sets of custom-designed primers (Supplementary Table S1). RT-PCR reactions were conducted following the instructions of Takara One Step Ex Taq qRT-PCR Kit (Clontech, U.S.A.). Once confirmed through electrophoresis on a $1.5 \%$ agarose gel, RT-PCR products were shipped to a sequencing service provider (Functional Biosciences, Madison, WI) for Sanger sequencing. The resultant genome sequence was assembled in both orientations using the SeqMan program in DNASTAR Lasergene 13 (Madison, WI). Finally, using the MegAlign program in DNASTAR Lasergene 13 with default parameters, pairwise analyses in the genetic relationship of the ToMMV isolate SC13-05 with seven other ToMMV isolates and four other tomato-infecting tobamoviruses (TMV, ToMV, ToMOHV, and TBRFV) were conducted using either their complete genome sequences, or their respective nucleotide and deduced amino acid sequences for each open reading frame. A phylogenetic relationship among the five tomato-infecting tobamoviruses was depicted using the MegAlign program in the DNASTAR Lasergene 13. A multiple sequence alignment was generated using the Clustal W method with complete genome nucleotide sequences of 13 representative virus isolates. A phylogenetic tree was created using the neighbor-joining methodology with 1,000 bootstraps.

Serological tests. Both commercial ELISA and ImmunoStrip kits for TMV and ToMV (Agdia, Elkhart, IN) were used to test for their serological cross-reactivity against ToMMV isolates following the manufacturer's instructions. Currently, a ToMMV-specific antibody is still not available. Thus, an ELISA kit for ToMV was initially used to determine positive virus infections on the inoculated plants in host range studies for both ToMV and ToMMV. A confirmation for specific virus infection was determined based on a species-specific multiplex RT-PCR described in the following.

Developing a multiplex RT-PCR for species-specific detection of TMV, ToMV, and ToMMV. To achieve species-specific detection, conserved sequence regions were identified from a multiplesequence alignment within each virus species, which would also be divergent significantly from other tomato-infecting tobamoviruses. Sets of species-specific primers designed for each TMV, ToMV, and ToMMV, respectively (Table 1) were also confirmed through in silico assessment by BLASTn analysis in the NCBI database. To allow for an easy identification, sizes of amplicons for each of three tobamoviruses were different for more than $250 \mathrm{bp}$, with predicted 866, 595, and 289 bp for TMV, ToMV, and ToMMV, respectively (Table 1). After testing in a simplex RT-PCR that each primer set was capable of amplifying its respective viral sequence, a multiplex RT-PCR was set up. Using a purified plant RNA preparation or a simple dilution of crude tissue extract in $0.1 \mathrm{M}$ Tris- $\mathrm{HCl}, \mathrm{pH} 8.0(\mathrm{Li}$ and Ling 2014), multiplex RT-PCR was performed using a Takara One Step Ex Taq qRT-PCR Kit (Clontech, U.S.A.). In each $20 \mu \mathrm{l}$ RT-PCR reaction, it consisted of $10 \mu \mathrm{l}$ of $2 \times$ master mix, $0.5 \mu \mathrm{l}$ Ex Taq HS mix ( $5 \mathrm{U} / \mu \mathrm{l}), 0.5 \mu \mathrm{l}$ RTase mix $(5 \mathrm{U} / \mu \mathrm{l}), 0.5 \mu \mathrm{l}$ of primer $\mathrm{P} 1(10 \mu \mathrm{M}), 0.5 \mu \mathrm{l}$ of $\mathrm{P} 2(10 \mu \mathrm{M}), 0.3 \mu \mathrm{l}$ of P3 $(10 \mu \mathrm{M}), 0.3 \mu \mathrm{l}$ of $\mathrm{P} 4$ $(10 \mu \mathrm{M}), 0.5 \mu \mathrm{l}$ of P5 $(10 \mu \mathrm{M}), 0.5 \mu \mathrm{l}$ of P6 $(10 \mu \mathrm{M})$, and $1 \mu \mathrm{l}$ of each RNA template. Thermal cycling reaction was carried out on a Mastercycler Nexus (Eppendorf, U.S.A.), with reverse transcription at $50^{\circ} \mathrm{C}$ for $30 \mathrm{~min}$ in 1 cycle, followed by denaturation at $95^{\circ} \mathrm{C}$ for $2 \mathrm{~min}$, and 35 cycles of $95^{\circ} \mathrm{C}$ for $1 \mathrm{~min}, 55^{\circ} \mathrm{C}$ for $1 \mathrm{~min}$, and $72^{\circ} \mathrm{C}$ for $1 \mathrm{~min}$, with a final extension at $72^{\circ} \mathrm{C}$ for $10 \mathrm{~min}$. RT-PCR products were analyzed through electrophoresis on a $1.5 \%$ agarose gel containing 1:10,000 SYBR Safe DNA Gel Stain (Thermo Fisher Scientific).

Comparative evaluation of disease resistance properties in selected tomato cultivars with resistance to ToMV and ToMMV. To understand whether tomato cultivars with ToMV resistance could 
also be resistant to ToMMV, we evaluated three commercial tomato cultivars (designated as 'B', 'E', and 'I' respectively, a gift from an anonymous seed company) with various levels of resistance to ToMV. Cultivar B is a cocktail tomato, cultivar E is a cluster tomato, and cultivar I is a mini San Marzano tomato. These tomato cultivars were screened for resistance along with a control cultivar Moneymaker in a greenhouse. Symptom appearance on the test plants was observed weekly post inoculation with a final reading at 6 weeks post inoculation (WPI). Besides such side-by-side comparative analysis for their resistance properties between the two viruses, additional experiments were conducted to demonstrate a resistance breaking occurred on the same test plants in cv. B. Test plants in cv. B were first inoculated with ToMV and demonstrated to be completely resistant. After 6 WPI, these same test plants were superinfected (a second mechanical inoculation) with ToMMV. Symptom expression on the test plants was observed for six additional weeks post second inoculation. In addition to symptom observation, positive virus infection was determined through lab tests using ToMV ELISA and the multiplex RT-PCR.

\section{Results}

Complete genome sequences of two new isolates of ToMMV in the U.S. and phylogenetic analysis. Complete genome sequences from two new isolates of ToMMV in the United States (one from California and another from South Carolina) were obtained. The complete genome sequence of ToMMV isolate SC13-05 (GenBank accession no. KX898033) was achieved through deep sequencing and assembly of sRNAs using the VirusDetect program (Zheng et al. 2017; http://bioinfo.bti.cornell.edu/tool/VirusDetect/), resulted in a single contig. In addition to ToMMV, a near complete genome

Table 1. Primers designed for species-specific detection of tomato-infecting tobamoviruses (TMV, ToMV, and ToMMV) in multiplex RT-PCR

\begin{tabular}{llcc}
\hline Primer & \multicolumn{1}{c}{ Sequence 5' $\mathbf{s}^{\prime}$} & Reference genome & Location \\
\hline P1, TMV-F & TAGCCGGTTTGGTCGTCACG & NC_001367 & $5108-5127$ \\
P2, TMV-R & ATGCACCTAACAGTGCTGTG & & $5973-5954$ \\
P3, ToMV-F & AAGATGTCAAACCAACTTTA & NC_002692 & $3640-3659$ \\
P4, ToMV-R & GAAACATCCAACTCAAGTACG & & $4234-4214$ \\
P5, ToMMV-F & CGACCCTGTAGAATTAATAAATATT & NC_022230 & $5775-5799$ \\
P6, ToMMV-R & CACTCTGCGAGTGGCATCCAAT & & $6063-6042$ \\
\hline
\end{tabular}

Table 2. Percentage nucleotide and amino acid sequence identity of tomato-infecting tobamoviruses in comparison with that of ToMMV SC13-05 (KX898033)

\begin{tabular}{|c|c|c|c|c|c|c|}
\hline Virus isolate & ORF1a ${ }^{\mathbf{a}}$ & ORF1b(RdRP $)^{\mathbf{a}}$ & ORF2(MP) $)^{\mathbf{a}}$ & $\operatorname{ORF3(CP})^{\mathbf{a}}$ & Genome $^{b}$ & Accession no. \\
\hline ToMMV CA16-01 & $99.4 / 99.7$ & $99.4 / 99.8$ & $98.9 / 99.3$ & $99.8 / 100.0$ & 99.4 & KX898034 \\
\hline ToMMV MX5 & $99.6 / 99.2$ & $99.6 / 99.4$ & $99.5 / 99.3$ & $99.8 / 100.0$ & 99.6 & KF477193 \\
\hline ToMMV NY13 & $99.5 / 99.3$ & $99.5 / 99.5$ & $99.8 / 99.6$ & $99.6 / 99.4$ & 99.5 & KT810183 \\
\hline ToMMV 10-100 & $99.6 / 99.6$ & $99.6 / 99.7$ & $99.4 / 99.3$ & $99.6 / 100.0$ & 99.5 & KM000122 \\
\hline ToMMV Israel-6742 & - & - & - & $99.8 / 99.4$ & - & KP861748 \\
\hline ToMMV Israel-3801 & - & - & - & $99.4 / 98.8$ & - & KP861747 \\
\hline ToMMV Capao Bonito & - & - & - & $99.6 / 100.0$ & - & KT222999 \\
\hline TMV Variant1 & $78.9 / 90.3$ & $80.1 / 91.6$ & $70.4 / 72.5$ & $76.5 / 83.1$ & 78.7 & V01408 \\
\hline ToMV Queensland & $84.7 / 94.2$ & $85.1 / 94.7$ & $78.5 / 81.5$ & $85.2 / 91.2$ & 84.3 & AF332868 \\
\hline TBRFV Tom1-Jo & $80.4 / 91.4$ & $81.8 / 92.1$ & $73.9 / 73.0$ & $80.2 / 86.2$ & 80.7 & KT383474 \\
\hline TMV Ohio V & $78.8 / 90.2$ & $80.5 / 91.2$ & $71.2 / 71.3$ & $78.1 / 82.5$ & 79.2 & FR878069 \\
\hline
\end{tabular}

a $\%$ nucleotide sequence identity / \% amino acid sequence identity.

b $\%$ nucleotide sequence identity.

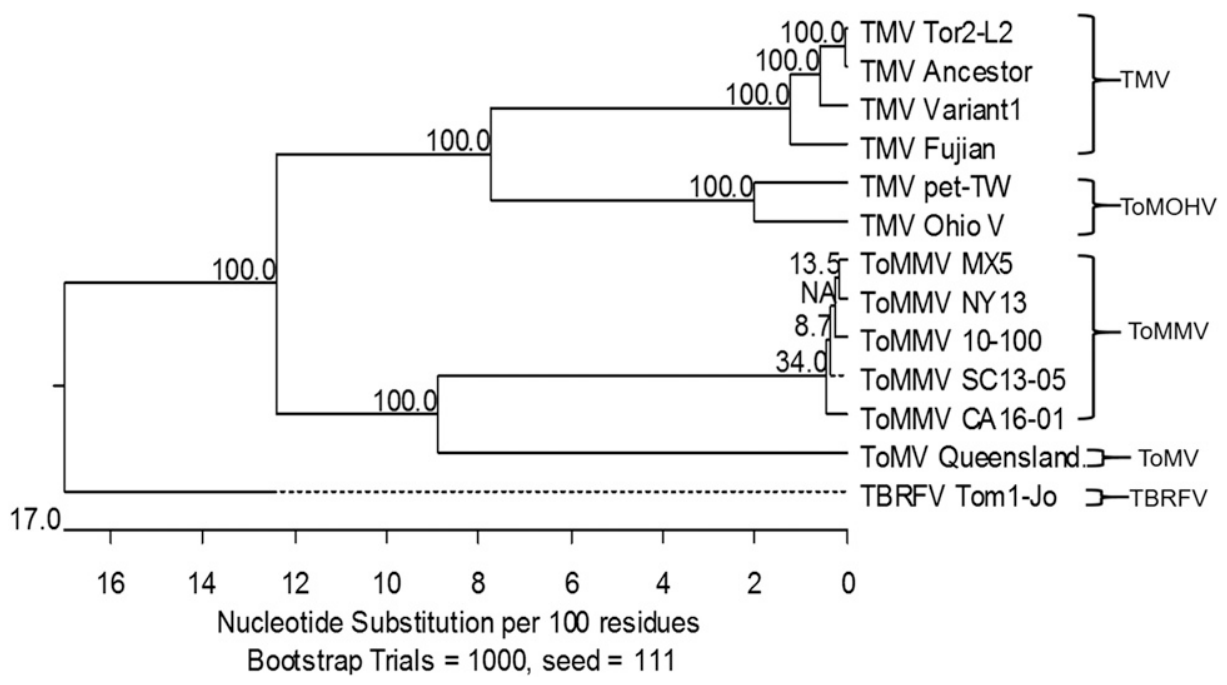

Fig. 1. Phylogenetic relationship of the five tomato-infecting tobamoviruses using complete genome nucleotide sequences of selected virus isolates. Virus isolates included in the alignment are as follow: ToMMV SC13-05 (KX898033); ToMMV CA16-01(KX898034); ToMMV MX5 (KF477193); ToMMV NY13 (KT810183); ToMMV 10-100 (KM000122); ToMV Queensland (AF332868); TMV Variant1 (V01408); TMV Tor2-L2 (KF972435); TMV Ancestor (KF972427); TMV Fujian (AF395127); TMV Ohio V (FR878069); TMV pet-TW (EF392659); TBRFV Tom1-Jo (KT383474). 
sequence of Southern tomato virus and a complete genome sequence of Potato spindle tuber viroid were also identified in the same tomato sample collected from a greenhouse near Charleston, SC, in 2013. For the ToMMV isolate CA16-01 (KX898034), a complete genome sequence was obtained through Sanger sequencing of 10 RT-PCR products generated using a series of ToMMV-specific primers. The size of complete genomes in both ToMMV isolates were the same, comprising 6,398 nucleotides. The genome contained four open reading frames (ORFs), in a typical tobamovirus organization (Adams et al. 2009). For each ToMMV isolate, $5^{\prime}$ and $3^{\prime}$ untranslated regions (UTR) consisted of $75 \mathrm{nt}$ and $200 \mathrm{nt}$, respectively. ORF1a encoded a 126-kDa protein as RNA-dependent RNA polymerase (RdRP). ORF1b encoded a $183-\mathrm{kDa}$ read-through protein. ORF2 encoded a movement protein (MP). ORF3 encoded a coat protein (CP). Comparative sequence analysis revealed a close genetic relationship among several ToMMV isolates. The ToMMV SC13-05 isolate shared 99.4 to $99.6 \%$ nucleotide sequence identity to that of other ToMMV isolates (Table 2). In comparison with other tomato-infecting tobamoviruses, the next strongest sequence identity to the ToMMV was $84.3 \%$ with that of ToMV isolates (Table 2). Pairwise comparisons of ToMMV, using nucleotide or deduced amino acid sequences in each respective ORF, also showed a closer relationship to ToMV than to several other tobamoviruses (Table 2). Among tomato-infecting tobamoviruses, greater sequence divergences were found in $\mathrm{CP}$ genes over that of MP genes, then followed by RdRP genes (Table 2). In phylogenetic analysis, the newly identified ToMMV SC13-05 and ToMMV CA16-01 isolates clustered with other ToMMV isolates and separated clearly from that of other tobamoviruses (Fig. 1). Interestingly,

Table 3. Serological cross reactivity of ToMMV to antibodies of TMV and ToMV in ELISA

\begin{tabular}{lcc}
\hline Sample & $\begin{array}{c}\text { TMV Ab } \\
\text { (OD mean } \pm \text { S.D.) }\end{array}$ & $\begin{array}{c}\text { ToMV Ab } \\
\text { (OD mean } \pm \text { S.D. })\end{array}$ \\
\hline ToMMV 1:10 & $1.43 \pm 0.05$ & $1.58 \pm 0.04$ \\
ToMMV 1:20 & $1.58 \pm 0.05$ & $1.79 \pm 0.04$ \\
ToMMV 1:40 & $1.49 \pm 0.11$ & $1.58 \pm 0.06$ \\
Healthy tomato & $-0.012 \pm 0.034$ & $-0.04 \pm 0.00$ \\
TMV control & $3.31 \pm 0.04$ & $0.23 \pm 0.03$ \\
ToMV control & $2.90 \pm 0.08$ & $3.31 \pm 0.01$ \\
\hline
\end{tabular}

a unique branch was assigned to the TMV Ohio V (GenBank accession no. FR878069) along with a petunia isolate of TMV from Taiwan in $96.3 \%$ genome nucleotide sequence identity (EF392659) separated from clusters containing other tobamoviruses $(86.5 \%$ to TMV, $79.6 \%$ to ToMV, $79.4 \%$ to ToMMV, and $82.2 \%$ to TBRFV) (Fig. 1). Based on the demarcation criteria for Tobamovirus species by the ICTV (Adams et al. 2012), TMV Ohio V, with $\leq 87 \%$ nucleotide sequence identity to that of other tobamoviruses, should be considered as a new species.

Serological cross reactivity among tomato-infecting tobamoviruses. In serological analysis using ToMMV-infected samples, a strong crossreactivity was observed when ImmunoStrip or ELISA reagents against TMV and ToMV were used. Using TMV ImmunoStrips, ToMMV was readily detected in crude leaf tissue extract prepared up to 1:1,280 in serial dilutions (Supplementary Fig. S1). When using TMV and ToMV ELISA reagents, absorbance readings were strong on samples that were infected with ToMMV (Table 3).

Multiplex RT-PCR for species-specific detection of three tobamoviruses. To evaluate effectiveness of the newly designed primers to offer sensitive detection against the respective target virus in simplex RT-PCR, expected amplicons of 866, 595, and 289 bp were generated for TMV, ToMV, and ToMMV, respectively (Fig. 2A). When three primer sets were included in a multiplex RT-PCR, three distinctive products in the expected size were observed (Fig. 2A). In specificity tests, the multiplex RT-PCR showed positive reactions to the target viruses, with no cross-reaction to nontarget viruses, including PepMV, TSWV, TCSV, TYLCV, CGMMV, PMMoV, PSTVd, and TBRFV (Fig. 2B). In a sensitivity test, the multiplex RT-PCR generated positive reactions in crude tissue samples that had been diluted up to 1:1,000 (Fig. 2C)

Expanded host range of ToMMV. To evaluate whether any differences in the host range could be identified between ToMV and ToMMV, in 27 plant species tested, similar plant species were infected by both ToMV and ToMMV, mainly in the Solanaceae family, such as tomato, Nicotiana benthamiana, N. rustica, N. tabacum 'Samsun', Physalis angulata, P. pubescens, and S. nigrum. In most of host species, symptoms induced on the infected plants were indistinguishable between the two viruses, including necrosis, chlorosis, mosaic, leaf distortion, and plant stunting (Table 4; Supplementary Fig. S2). Five plant species in the Amaranthaceae family produced local lesions on the inoculated leaves, with some spreading to the
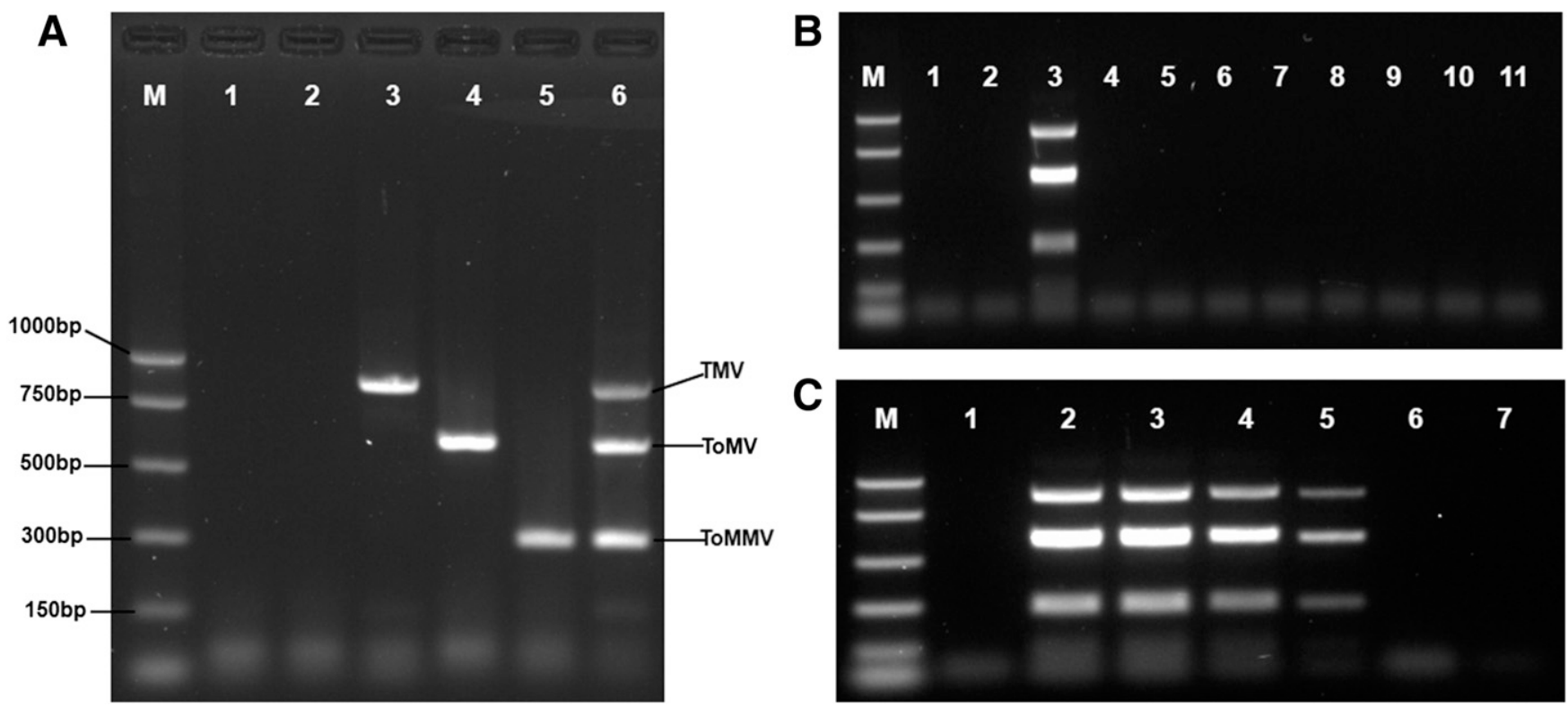

Fig. 2. Development of a multiplex RT-PCR for species-specific detection of TMV, ToMV, and ToMMV. PCR products were analyzed through electrophoresis on a $1.5 \%$ agarose gel. A, Development of the detection method. M: PCR marker; lane 1: nontemplate control; lane 2: healthy control; lane 3: TMV; lane 4: ToMV; lane 5: ToMMV; lane 6: TMV, ToMV, and ToMMV in mixed infection. B, Specificity of the multiplex RT-PCR. M: PCR marker; lane 1: nontemplate control; lane 2: healthy control; lane 3: TMV, ToMV and ToMMV mixed infection as positive control; lane 4: PepMV; lane 5: TSWV; lane 6: TCSV; lane 7: TYLCV; lane 8: CGMMV; lane 9: PMMoV; lane 10: PSTVd; lane 11: TBRFV. C, Sensitivity of the multiplex RT-PCR. M: PCR marker; lane 1: nontemplate control; crude tissue extract was diluted in tenfold increments from 1:1 (lane 2) to 1:10 (lane 7). 
systemic leaves. In addition to symptom observation, the presence of a specific virus was determined using ToMV-ELISA and confirmed by the multiplex RT-PCR. Through these tests, we found that Verbena officinalis var. halei, which showed no visible sign of systemic infection, was a host in latent infection by both ToMV and ToMMV. Interestingly, we also observed two plant species with differential responses to ToMMV infection. While $N$. tabacum 'Xanthi nc' inoculated by ToMV produced local lesions on the inoculated leaves with no systemic infection, a systemic infection with slight mosaic appearance was detected on $N$. tabacum 'Xanthi nc' inoculated by ToMMV (Fig. 3B). In another case, while Datura stramonium was resistant to ToMV, it was very susceptible to ToMMV infection. ToMMVinoculated $D$. stramonium plants expressed severe leaf necrosis and died quickly, within 1 week post inoculation (Fig. 3A). These results demonstrated a broader host range for ToMMV than that of ToMV.

Resistance breaking in a ToMV-resistant tomato cultivar by ToMMV. To evaluate whether ToMV-resistant commercial tomato cultivars were also resistant to ToMMV, a control cultivar Moneymaker and three commercial tomato cultivars ('B', 'E', and 'I') with various levels of resistance to ToMV were screened with ToMMV and ToMV. The resistance screening was conducted in three separate experiments, with similar percentage of plants infected (Table 5). While plants in cv. I were susceptible to ToMV and ToMMV, plants in cv. E were resistant. However, plants in cv. B responded differently when inoculated by ToMV or ToMMV. While all test plants in cv. B exhibited full resistance to ToMV, a similar portion of plants inoculated with ToMMV showed disease symptoms from each of the three experiments. In the first experiment, three of 12 plants inoculated with ToMMV broke the resistance by exhibiting necrotic lesions on noninoculated leaves at 4 WPI (Fig. 4A; Table 5). In the second experiment, similar proportion of test plants were infected by ToMMV, suggesting the possibility of a resistance breaking in cv. B. To confirm the phenomena of resistance breaking by ToMMV in cv. B, a larger number of seedlings were tested in the third experiment. In total, among 148 plants tested, 15 (approximately $10 \%$ ) were susceptible to ToMMV infection. The species-specific RT-PCR detected the presence of ToMMV in those susceptible cv. B plants (data not shown). Once infected, those susceptible plants were seriously stunted and their flowers aborted, resulting in no fruit production (Fig. 4).

Although the resistance breaking phenomena on tomato cv. B by ToMMV were quite consistent, these results offered only indirect evidence, because inoculation experiments for ToMV and ToMMV were conducted on two separate sets of seedlings from the same seed lot. To provide direct evidence to support the true resistance breaking would be to screen the same test plants with two viruses in subsequent inoculations, first by ToMV and followed by ToMMV. From 12 plants with resistance to ToMV in the third experiment (Table 5), one of these plants was infected by ToMMV with typical disease

Table 4. Comparative evaluation of experimental host range between ToMMV and ToMV

\begin{tabular}{|c|c|c|c|c|c|}
\hline \multirow[b]{2}{*}{ Family, species, cultivar } & \multirow[b]{2}{*}{ Common name } & \multicolumn{2}{|c|}{ ToMMV } & \multicolumn{2}{|c|}{ ToMV } \\
\hline & & Symptoms $^{a}$ & RT-PCR $^{\mathbf{b}}$ & Symptoms $^{a}$ & RT-PCR $^{b}$ \\
\hline \multicolumn{6}{|l|}{ Amaranthaceae } \\
\hline Chenopodium album & Lamb's quarters & CLL/- & - & CLL/M,D & + \\
\hline Chenopodium berlandieri & Lamb's quarters & CLL/- & - & CLL/M & + \\
\hline Chenopodium giganteum & Three spinach & CLL/- & - & CLL/C & + \\
\hline Chenopodium quinoa & Quinoa & CLL/CL & + & NLL/M,PD & + \\
\hline Gomphrena globosa & Globe amaranth & NRS/M & + & $-/ \mathrm{M}$ & + \\
\hline \multicolumn{6}{|l|}{ Apocynaceae } \\
\hline Catharanthus roseus & Rosy periwinkle & $-1-$ & - & NA & NA \\
\hline \multicolumn{6}{|l|}{ Asteraceae } \\
\hline Emilia sonchifolia & Lilac tasselflower & $-1-$ & - & $-1-$ & - \\
\hline Glebionis coronaria & Crown daisy & $-1-$ & + & NA & NA \\
\hline Lactuca sativa & Lettuce & $-1-$ & - & $-1-$ & - \\
\hline \multicolumn{6}{|l|}{ Brassicaceae } \\
\hline Brassica rapa & Field mustard & $-1-$ & - & $-1-$ & - \\
\hline \multicolumn{6}{|l|}{ Cucurbitaceae } \\
\hline Citrullus lanatus 'Charleston Gray' & Watermelon & $-1-$ & - & NA & NA \\
\hline Cucumis melon & Cantaloupe & $-1-$ & - & $-1-$ & - \\
\hline Cucumis metulifer & Horned melon & $-1-$ & - & $-1-$ & - \\
\hline Cucurbita moschata & Butternut squash & $-1-$ & - & NA & NA \\
\hline \multicolumn{6}{|l|}{ Solanaceae } \\
\hline Nicotiana benthamiana & & -/M,D,PD & + & NA & NA \\
\hline Datura stramonium & Jimsonweed & $-/ \mathrm{N}, \mathrm{PD}$ & + & $-1-$ & - \\
\hline Nicotiana debneyi & Debney's tobacco & NLL/- & - & CLL/- & - \\
\hline Nicotiana rustica & Aztec tobacco & $-/ \mathrm{M}, \mathrm{PD}$ & + & $-/ M, P D$ & + \\
\hline Nicotiana tabacum 'Samsun' & Tobacco & $-/ \mathrm{M}$ & + & $-/ \mathrm{M}$ & + \\
\hline Nicotiana tabacum 'Xanthi nc' & Tobacco & NLL/M & + & NLL/- & - \\
\hline Petunia $x$ hybrida & Garden petunia & NLL/- & + & NA & NA \\
\hline Physalis angulata & Cutleaf groundcherry & NLL/M & + & NLL/PD,M & + \\
\hline Physalis pubescens & Husk tomato & CLL/M & + & CLL/M & + \\
\hline Solanum lycopersicum 'Moneymaker' & Tomato & $-/ \mathrm{M}, \mathrm{D}$ & + & $-/ \mathrm{M}$ & + \\
\hline Solanum melongena & Eggplant & NLL/- & - & NLL/- & - \\
\hline Solanum nigrum & Black nightshade & CLL/YM & + & $-/ \mathrm{M}$ & + \\
\hline \multicolumn{6}{|l|}{ Verbenaceae } \\
\hline Verbena officinalis var. halei & Common verbena & $-1-$ & + & $-1-$ & + \\
\hline
\end{tabular}

a Symptoms observed on inoculated and noninoculated leaves are indicated to the left and right of the slash, respectively. $-=$ no symptoms, CLL $=$ chlorotic local lesion, $\mathrm{CL}=$ chlorotic lesion, $\mathrm{C}=$ chlorosis, $\mathrm{NLL}=$ necrotic local lesion, $\mathrm{NL}=$ necrotic lesion, $\mathrm{N}=$ necrosis, $\mathrm{M}=$ mosaic, $\mathrm{D}=$ distortion, $\mathrm{PD}=$ plant death, $\mathrm{NRS}=$ necrotic ringspot, $\mathrm{YM}=$ yellow mosaic, $\mathrm{NA}=$ not available.

${ }^{\mathrm{b}}$ Indicate the presence of virus in upper, noninoculated leaves. All systemic infections were confirmed by species-specific RT-PCR for ToMV and ToMMV. - = negative results; $+=$ positive results. 

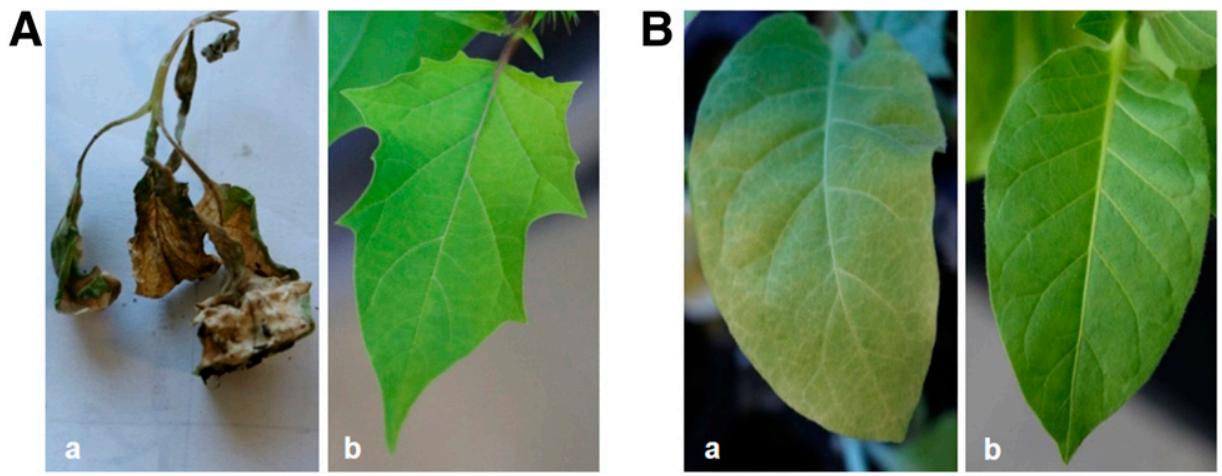

Fig. 3. Differential responses of selected host plants inoculated by ToMMV or ToMV. A, Symptoms on Datura stramonium (jimsonweed) a. ToMMV; b. ToMV. B, Symptoms on Nicotiana tabacum 'Xanthi nc': a. ToMMV; b. ToMV.

Table 5. Comparative evaluation of tomato cultivars for resistance to ToMMV and ToMV and identification of resistance breaking on cv. B by ToMMV

\begin{tabular}{|c|c|c|c|c|c|c|c|c|c|c|c|c|}
\hline \multirow[b]{2}{*}{ Cultivar } & \multicolumn{4}{|c|}{ ToMMV } & \multicolumn{4}{|c|}{ ToMV } & \multicolumn{4}{|c|}{ Buffer } \\
\hline & First $^{\mathbf{a}}$ & Second $^{\mathrm{a}}$ & Third $^{\mathrm{a}}$ & Mean infection $^{\mathbf{b}}$ & First $^{\mathbf{a}}$ & Second $^{\mathbf{a}}$ & Third $^{\mathrm{a}}$ & Mean infection $^{b}$ & First $^{\mathbf{a}}$ & Second $^{\mathrm{a}}$ & Third $^{\mathrm{a}}$ & Mean infection $^{b}$ \\
\hline $\mathrm{E}$ & $0 / 12$ & $0 / 6$ & $0 / 5$ & $0 \%$ & $0 / 12$ & $0 / 4$ & $0 / 9$ & $0 \%$ & $0 / 12$ & $0 / 3$ & $0 / 1$ & $0 \%$ \\
\hline B & $3 / 12$ & $3 / 6$ & $15 / 148$ & $12.65 \%$ & $0 / 12$ & $0 / 6$ & $0 / 12$ & $0 \%$ & $0 / 12$ & $0 / 5$ & $0 / 6$ & $0 \%$ \\
\hline I & $10 / 12$ & $5 / 6$ & $5 / 5$ & $86.96 \%$ & $11 / 12$ & $6 / 6$ & $12 / 12$ & $96.67 \%$ & $0 / 12$ & $0 / 5$ & $0 / 3$ & $0 \%$ \\
\hline $\mathrm{Mm}^{\mathrm{c}}$ & $12 / 12$ & $6 / 6$ & $6 / 6$ & $100 \%$ & $12 / 12$ & $5 / 5$ & $8 / 8$ & $100 \%$ & $0 / 12$ & $0 / 5$ & $0 / 1$ & $0 \%$ \\
\hline
\end{tabular}

${ }^{\mathrm{a}}$ Number of plants infected/total number of plants inoculated.

${ }^{\mathrm{b}}$ Percentage of plants infected in total number of plants inoculated.

${ }^{\mathrm{c}} \mathrm{Mm}=$ Moneymaker.
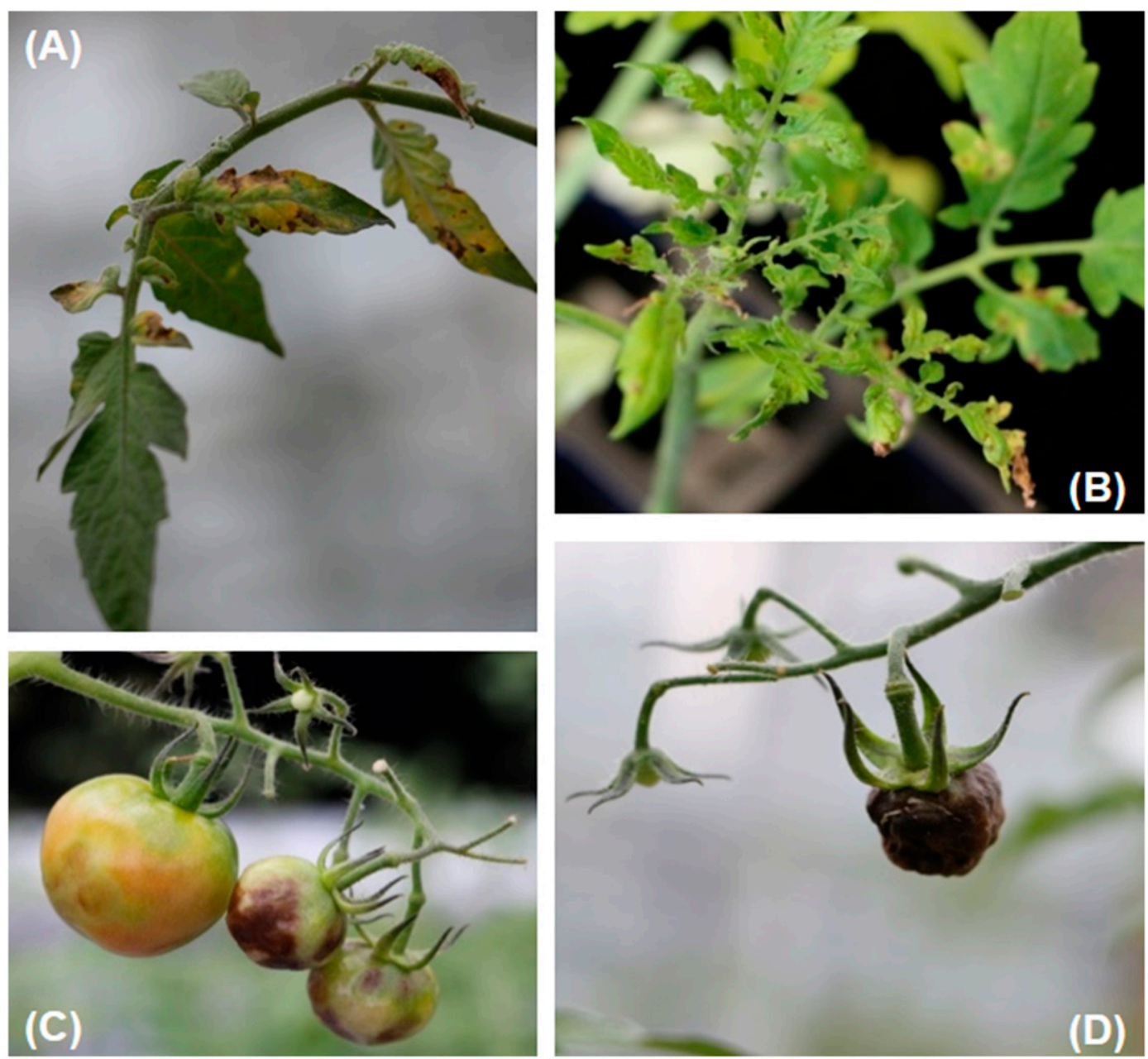

Fig. 4. Typical symptoms on susceptible cv. B tomato plants infected by ToMMV. A, necrotic lesions and chlorosis on leaves; B, leaf deformation; C, necrotic lesions on fruits; D, fruit necrosis. 
symptoms (Fig. 4). On that resistance-breaking plant, ToMMV, but not ToMV, was detected using species-specific multiplex RT-PCR.

\section{Discussion}

We reported here the complete genome sequences of two new isolates of ToMMV collected in South Carolina and California, respectively. In the United States, ToMMV has been reported in Florida (Fillmer et al. 2015) and New York (Padmanabhan et al. 2015). The ToMMV isolate SC13-05 shares 99.4 to $99.6 \%$ nucleotide sequence identity to that of the other known ToMMV isolates, but with less than $85 \%$ to four other tomato-infecting tobamoviruses, including $78.7 \%$ to TMV, $84.3 \%$ to ToMV, $80.7 \%$ to TBRFV, and $79.2 \%$ to TMV Ohio V (Table 2). The lack of genetic diversity among ToMMV isolates may reflect the recent emergence of this novel virus (Li et al. 2013) as well as the relative smaller number of isolates ( $\mathrm{Li}$ et al. 2014; Turina et al. 2016) that have been identified and sequenced to date.

The TMV isolate Ohio V, which breaks resistance in tomato carrying $T m-1$ and $T m$-2, was originally collected from Ohio in 1969 (Cirulli and Alexander 1969). Recently, the full genome of this virus has been sequenced (GenBank accession no. FR878069; Körbelin et al. 2012). Our analysis showed $\leq 87 \%$ sequence identity to all other TMV isolates. Based on the ICTV demarcation criteria for tobamoviruses, a complete virus genome with less than $90 \%$ nucleotide sequence identity to other known viruses should be considered as a new species (Adams et al. 2012). Since TMV Ohio V has a clear separation from other tobamovirus clusters (with genome nucleotide sequence identities of $86.5 \%$ to TMV, $79.6 \%$ to ToMV, $79.4 \%$ to ToMMV, and $82.2 \%$ to TBRFV) (Fig. 1), as well as its distinct biological property in overcoming the resistance in tomato cultivars carrying the Tm-1 and Tm-2 genes (Cirulli and Alexander 1969; Körbelin et al. 2012), we propose to consider TMV Ohio V as a new species of tobamovirus, provisionally named Tomato mosaic Ohio virus (ToMOHV).

With their strong serological cross-reactivity among several tomato-infecting tobamoviruses, a positive serological result from ELISA or a lateral flow device would not make definite identification for a specific virus. To achieve a reliable disease diagnosis at virus species level, a sensitive and species-specific multiplex RT-PCR method was developed in the present study and demonstrated to make positive identification for the three common tomato infecting tobamoviruses, without the need for additional sequencing (Fig. 2). In silico analysis revealed a strong sequence divergence by the ToMMV-specific F2 primer, with $7 / 25$ substitutions (or only $72 \%$ nucleotide sequence identity) to ToMOHV and 3/25 substitutions (or $88 \%$ identity in the primer region) to TBRFV. Similarly, for ToMMV-specific R1 primer, there were 4/22 substitutions (or $82 \%$ identity in the primer region) to ToMOHV or $6 / 22$ substitutions (73\% identity in the primer region) to TBRFV. To ensure a species-specific detection, the $3^{\prime}$ terminal sequences of the forward and reverse primers were also in divergence to other four tomatoinfecting tobamoviruses. A similar strategy was employed to design primers specific for RT-PCR detection of TMV and ToMV. The successful application of this multiplex RT-PCR for species-specific virus detection on various plant species in the host range experiments also demonstrated its potential for practical disease diagnosis and virus detection.

In comparative host range studies, ToMMV could systemically infect nine solanaceous species, while ToMV could only induce symptoms in seven of them. ToMMV could cause systemic infection on $N$. tabacum 'Xanthi nc' and D. stramonium (jimsonweed), even though systemic infection was not observed on these two species by ToMV (Table 4). Such broader host range suggests that ToMMV is more virulent than ToMV. Jimsonweed is an annual plant species commonly found near agricultural fields. ToMV only induced necrotic lesions on inoculated leaves, but ToMMV induced systemic infection on jimsonweed plants (Fig. 3). Such unique biological properties would likely increase the future occurrences of ToMMV in the field.

In the evaluation of tobamovirus-resistant tomato cultivars, ToMMV could overcome the ToMV resistance in tomato cv. B in a small proportion of the test plants (approximately 10\%). This resistance breaking was validated on the same test plants showing ToMV resistance by a superinfection (with a second inoculation) using ToMMV. This resistance breaking is a major concern to the tomato industry and seed companies. It is likely that with a broader adaptation of the species-specific detection developed in the present study and with additional virus survey conducted in other countries, a greater geographic distribution of ToMMV in the world is likely to emerge. With the understanding of unique biological characteristics of ToMMV, its expanded host range, and resistance breaking on certain tomato cultivars, efforts to search for new sources of genetic resistance to ToMMV, as well as to two other emerging tobamoviruses (TBRFV and ToMOHV), would be necessary. In future studies, genetic inheritance of resistance and molecular markers will be determined to facilitate tomato breeding for resistance to ToMMV.

\section{Acknowledgments}

We thank Dr. Daniel Hasegawa for critical reading to the manuscript and Andrea Gilliard for her excellent technical assistance. This work was supported in part by grants from the USDA, National Institute of Food and Agriculture's Specialty Crop Research Initiative program SCRI 2010-600-25320 and 2012-01507229756 to KSL. A generous scholarship provided to X.S. by the China Scholarship Council (No. 201408350066) is greatly appreciated.

\section{Literature Cited}

Adams, M. J., Antoniw, J. F., and Kreuze, J. 2009. Virgaviridae: a new family of rod-shaped plant viruses. Arch. Virol. 154:1967-1972.

Adams, M. J., Heinze, C., Jackson, A. O., Kreuze, J. F., Macfarlane, S. A., and Torrance, L. 2012. Pages 1139-1162 in: Virus Taxonomy: Ninth Report of the International Committee on Taxonomy of Viruses. Elsevier/Academic Press, London.

Chen, C.-J., Servant, N., Toeding, J., Sarazin, A., Marchais, A., DuvernoisBerthet, E., Cognat, V., Colot, V., Voinnet, O., Heard, E., Ciaudo, C., and Barillot, E. 2012. ncPRO-seq: a tool for annotation and profiling of ncRNAs in sRNA-seq data. Bioinformatics 28:3147-3149.

Chitra, T. R., Prakash, H. S., Albrechtsen, S. E., Shetty, H. S., and Mathur, S. B. 2002. Indexing of leaf and seed samples of tomato and bell pepper for tobamoviruses. Indian Phytopath. 55:84-86.

Cirulli, M., and Alexander, L. J. 1969. Influence of temperature and strain of tobacco mosaic virus on resistance in a tomato breeding line derived from Lycopersicon peruvianum. Phytopathology 59:1287-1297.

Fillmer, K., Adkins, S., Pongam, P., and D'Elia, T. 2015. Complete genome sequence of a tomato mottle mosaic virus isolate from the United States. Genome Announc. 3:e00167-15.

Foolad, M. R., and Panthee, D. R. 2012. Marker-assisted selection in tomato breeding. Crit. Rev. Plant Sci. 31:93-123.

Hajiabadi, A. M., Asaei, F., Mandoulakani, B. A., and Rastgou, M. 2012. Natural incidence of tomato viruses in the North of Iran. Phytopathol. Mediterr. 51: 390-396.

Hamamoto, H., Watanabe, Y., Kamada, H., and Okada, Y. 1997. Amino acid changes in the putative replicase of tomato mosaic tobamovirus that overcome resistance in Tm-1 tomato. J. Gen. Virol. 78:461-464.

Hanssen, I. M., Lapidot, M., and Thomma, B. P. H. J. 2010. Emerging viral diseases of tomato crops. Mol. Plant-Microbe Intact. 23:539-548.

Imran, M., Khan, M. A., Azeem, M., Ahmed, N., Binyamin, R., and Riaz, A. 2012. Screening of tomato germplasm for the source of resistance and its management against ToMV [2012]. Pak. J. Phytopathol. 24:53-57.

Jacobi, V., Bachand, G. D., Hamelin, R. C., and Castello, J. D. 1998. Development of a multiplex immunocapture RT-PCR assay for detection and differentiation of tomato and tobacco mosaic viruses. J. Virol. Methods 74:167-178.

Körbelin, J., Willingmann, P., Adam, G., and Heinze, C. 2012. The complete sequence of tobacco mosaic virus isolate Ohio reveals a high accumulation of silent mutations in all open reading frames. Arch. Virol. 157:387-389.

Kumar, S., Udaya Shankar, A. C., Nayaka, S. C., Lund, O. S., and Prakash, H. S. 2011. Detection of Tobacco mosaic virus and Tomato mosaic virus in pepper and tomato by multiplex RT-PCR. Lett. Appl. Microbiol. 53:359-363.

Lanfermeijer, F. C., Dijkhuis, J., Sturre, M. J., Haan, P., and Hille, J. 2003. Cloning and characterization of the durable tomato mosaic virus resistance gene $\mathrm{Tm}-2^{2}$ from Lycopersicon esculentum. Plant Mol. Biol. 52:1039.

Lefeuvre, P., Martin, D. P., Harkins, G., Lemey, P., Gray, A. J. A., Meredith, S., Lakay, F., Monjane, A., Lett, J.-M., Varsani, A., and Heydarnejad, J. 2010. The spread of Tomato yellow leaf curl virus from the Middle East to the world. PLoS Pathog. 6:e1001164.

Letschert, B., Adam, G., Lesemann, D.-E., Willingmann, P., and Heinze, C. 2002 Detection and differentiation of serologically cross-reacting tobamoviruses of economical importance by RT-PCR and RT-PCR-RFLP. J. Virol. Methods 106:1-10 
Li, R., Gao, S., Fei, Z., and Ling, K.-S. 2013. Complete genome sequence of a new tobamovirus naturally infecting tomatoes in Mexico. Genome Announc. 1:e00794-13.

Li, R., and Ling, K.-S. 2014. Development of reverse transcription loop-mediated isothermal amplification assay for rapid detection of an emerging potyvirus: Tomato necrotic stunt virus. J. Virol. Methods 200:35-40.

Li, Y. Y., Wang, C. L., Xiang, D., Li, R. H., Liu, Y., and Li, F. 2014. First report of tomato mottle mosaic virus infection of pepper in China. Plant Dis. 98:1447.

Liu, G., Liu, Y., Gong, Q., Yang, X., Kang, L., and Tian, B. 1999. The construction of plant expression vectors harboring TMV-L MP gene and interaction between the MP gene and Tm-2(2) resistance gene in transgenic tomato. J. Agric. Biotechnol. 7:11-15.

Ohmori, T., Murata, M., and Motoyoshi, F. 1996. Molecular characterization of RAPD and SCAR markers linked to the Tm-1 locus in tomato. Theor. Appl. Genet. 92:151.

Padmanabhan, C., Zheng, Y., Li, R., Martin, G. B., Fei, Z., and Ling, K.-S. 2015. Complete genome sequence of a tomato-infecting Tomato mottle mosaic virus in New York. Genome Announc. 3:e01523-15.

Pelham, J. 1966. Resistance in tomato to tobacco mosaic virus. Euphytica 15:258-267.

Salem, N., Mansour, A., Ciuffo, M., Falk, B. W., and Turina, M. 2016. A new tobamovirus infecting tomato crops in Jordan. Arch. Virol. 161:503.

Shi, A., Vierling, R., Grazzini, R., Chen, P., Caton, H., and Panthee, D. 2011. Molecular markers for Tm-2 alleles of Tomato mosaic virus resistance in tomato. Am. J. Plant Sci. 2:180-189.

Strasser, M., and Pfitzner, A. J. P. 2007. The double-resistance-breaking Tomato mosaic virus strain $\mathrm{ToMV}_{1-2}$ contains two independent single resistancebreaking domains. Arch. Virol. 152:903.
Tentchev, D., Verdin, E., Marchal, C., Jacquet, M., Aguilar, J. M., and Moury, B. 2011. Evolution and structure of Tomato spotted wilt virus populations: evidence of extensive reassortment and insights into emergence processes. J. Gen. Virol. 92:961-973.

Turina, M., Geraats, B. P. J., and Ciuffo, M. 2016. First report of Tomato mottle mosaic virus in tomato crops in Isreal. New Dis. Rep. 33:1

USDA-NASS. 2015. Agricultural Statistics. United State Department of Agriculture, National Agricultural Statistics Service. Online: https://www.nass.usda.gov/ Data_and_Statistics/

Weber, H., Ohnesorge, S., Silber, M. V., and Pfitzner, A. J. P. 2004. The Tomato mosaic virus $30 \mathrm{kDa}$ movement protein interacts differentially with the resistance genes Tm-2 and Tm- $2^{2}$. Arch. Virol. 149:1499.

Weber, H., Schultze, S., and Pfitzner, A. J. 1993. Two amino acid substitutions in the tomato mosaic virus 30-kilodalton movement protein confer the ability to overcome the Tm-2 (2) resistance gene in the tomato. J. Virol. 67:6432-6438.

Webster, C. G., Frantz, G., Reitz, S. R., Funderburk, J. E., Mellinger, H. C., McAvoy, E., Turechek, W. W., Marshall, S. H., Tantiwanich, Y., McGrath, M. T., Daughtrey, M. L., and Adkins, S. 2015. Emergence of Groundnut ringspot virus and Tomato chlorotic spot virus in vegetables in Florida and the southeastern United States. Phytopathology 105:388-398.

Young, N. D., Zamir, D., Ganal, M. W., and Tanksley, S. D. 1988. Use of isogenic lines and simultaneous probing to identify DNA markers tightly linked to the tm-2a gene in tomato. Genetics 12:579-585.

Zheng, Y., Gao, S., Padmanabhan, C., Li, R., Galvez, M., Gutierrez, D., Fuentes, S., Ling, K.-S., Kreuze, J., and Fei, Z. 2017. VirusDetect: an automated pipeline for efficient virus discovery using deep sequencing of small RNAs. Virology 500:130-138 